\title{
Trends in the twinning rate in Johannesburg, South Africa, 1969-1989 and estimated twinning rates for 1990
}

\author{
Frances M Hain and Jennifer GR Kromberg
}

Department of Human Genetics, School of Pathology, South African Institute for Medical Research and University of the Witwatersrand, Jhannesburg, South Africa

\begin{abstract}
Birth statistics for the Johannesburg Metropolitan Region were collected for 757151 confinements from 1969 to 1989 (467513 Black, 194375 White, 67250 Coloured and 28013 Indian confinements). From 1969 to 1978 data on the sexes of twins were also collected for 375203 of the confinements (203504 Black, 129631 White, 28253 Coloured and 13815 Indian confinements). A twin confinement was defined as two deliveries during one confinement. Twinning rates (TRs), defined as the number of twin confinements per 1000 total confinements, were calculated per year for each population group and from 1969-1978 estimates of the relative proportions of dizygotic (DZ) and monozygotic (MZ) twins were calculated and thus the relative DZTRs and MZTRs. A significant decline in Black and Coloured TRs was observed between 1969 and 1989. A significant decline in Black DZTR but not Black MZTR was observed between 1969 and 1978, the Coloured twin sample was too small to show significant trends over this period. It is probable that the overall decline in Black twinning may be explained by a decline in the DZTR. An analysis of birth statistics for 159748 confinements (134504 Black and 25244 White confinements) collected as part of a prospective study of TRs in the Johannesburg Metropolitan Region from 1988 to 1990, indicated that the Black TR continued to decline at least until the end of 1990. TRs in the Johannesburg Metropolitan Region calculated from City Health Department birth statistics collected from 1988 to 1990 were: 13.8 and 10.77 for the Black and White populations, respectively. TRs for this period calculated from the combined birth statistics of 14 hospitals, nursing homes and maternity clinics across the region were: 12.4 and 10.88 for the Black and White populations, respectively.
\end{abstract}

Keywords: twins, twinning rate, trends, South Africa, africans

\section{Introduction}

There has been much speculation over the widespread decline in the twinning rate (TR) during the twentieth century. In several countries this decline appears to have started at some time during the past 50 years. ${ }^{1}$ How ever, there are some exceptions to this trend. Swedish research indicates that the TR in Sweden began to decline in the nineteenth century, but a significant decline in Finnish TR was not observed until the 1960 s. $^{2}$ Parisi and Caperna ${ }^{3}$ report a continuous decline in TR in northern Italy for almost a hundred years, whilst in the south of Italy the dizygotic twinning rate (DZTR) increased to a peak in the 1950s and then declined.

Data from the USA, United Kingdom, Australia, Italy, Denmark, Poland, and Japan have suggested that the decline in TR in these countries ceased in the 1970 s and then gradually increased to the early 1980 s stabilising thereafter. ${ }^{4-9}$

Correspondence: Professor JGR Kromberg, South African Institute for Medical Research, University of the Witwatersrand, PO Box 1038, Johannesburg 2000, South Africa. Tel: 27114899213

Received 4 December 1997; accepted 25 February 1998
The decline in TR observed worldwide appears to be accounted for mainly by a decline in the DZTR. $^{7,10-12}$ However, some decrease in the monozygotic twinning rate (MZTR) has also been reported. ${ }^{1,11}$ and recent increases in TR have been attributed to increases in both $M Z$ and $D Z$ twinning. ${ }^{1,5,7}$

The aim of this study was to examine the trends in TR in four South African population groups. These are the so-called 'Black', 'White', 'Indian' and 'Coloured' populations of South Africa.

The South African Black population is primarily Negroid. However, all the Negro peoples of the eastern part of Southern Africa have interbred to some extent with the Khoisan, the Khoi component varying among different ethnic groups. ${ }^{13}$ The White population of South Africa, for the most part, constitutes Caucasoid people of European origin. A small number of Mongoloid people are al so included in the White population, these are the Chinese South Africans. ${ }^{13}$ The Indians of South Africa are Caucasoid with some admixture of genes from the 'Aboriginal' peoples of the subcontinent. ${ }^{13}$ Finally the term 'Coloured' in South Africa is used to describe the people of mixed racial origin into whose ancestry a 
Caucasoid element has entered. The other el ement is generally African in origin but may be Khoi, west African Negro, southern African Negro or San. Slaves brought to South Africa from the Malay peninsular have al so added a Mongoloid element to this population. The category 'Coloured' is, therefore, the most heterogeneous of the four broad population classes used in this study.

\section{Materials and methods}

Data on the total number of confinements and number of twin confinements occurring in the Johannesburg Metropolitan Region were obtained from the Birth Records Office of the Johannesburg City Heal th Department. The data covered the period from 1 January 1969 to 31 December 1989. From January 1990 onwards the Johannesburg City Heal th Department no longer received the birth notifications for the majority of the Black population of the Jhannesburg Metropolitan Region. For this reason the retrospective study was only continued until December 1989. However, from January 1988 to December 1990 birth statistics were collected from 14 hospitals, nursing homes and maternity clinics across the Jhannesburg Metropolitan Region as part of a prospective twin study. ${ }^{14}$ These data, al ong with data from the Johannesburg City Heal th Department, were used to estimate the TRs in this region of South Africa until the end of 1990. For the purpose of this study, the twinning rate is defined as the number of twin confinements recorded per thousand total confinements in a particular set of birth records; where a confinement constitutes the delivery of one infant, alive or dead, and a twin confinement constitutes the delivery of twin infants, alive or dead. ${ }^{14}$

The use of hospital birth statistics for a study of twinning rates may involve a bias due to the fact that the maternity wards of hospital s often contain a high proportion of 'referred' cases, ie cases which are considered high risk pregnancies and so may include a disproportionate number of twin and other multiple deliveries. Despite this fact it was decided to include two general hospitals in the study. All twin and other multiple pregnancies presenting at the surrounding maternity clinics are automatically referred to these two hospitals. This means that the birth statistics of the hospitals al one represent a very biased sample with respect to multiple births. However, by combining the total birth statistics of these hospitals with those of the surrounding maternity clinics (which include records of home deliveries supervised by a midwife) a more accurate estimate could be made of the birth statistics for the whole of this region of South Africa.
Birth statistics for 757151 confinements were collected for the 21-year period from 1969 to 1989. These included 467513 Black, 194375 White, 67250 Coloured and 28013 Indian confinements. For the 10-year period from 1969 to 1978 birth statistics had to be drawn directly from the birth notification record books of the Johannesburg City Health Department, as no annual summaries were available. This exercise provided additional information on the sex of the child or children born for 375203 confinements among the total confinements included in the study. These included 203504 Black, 129631 White, 28253 Coloured and 13815 Indian confinements. By applying the Weinberg method to the data collected, it was possible to estimate the relative proportions of $\mathrm{MZ}$ and $\mathrm{DZ}$ twins born during the 10-year period from 1969 to 1978 . As a total of only 440 twin pairs were born to the members of the Coloured and Indian populations of the Johannesburg Metropolitan Region (308 and 132 respectively) during this 10-year period, this sample was considered too small to provide an accurate estimate of the trends in $M Z$ and $D Z$ twinning rates within each of these populations individually. The birth statistics for these populations were, however, included in the analysis of TR trends in the overall population of the Johannesburg Metropolitan Region.

For the 3-year period from 1988 to 1990 birth statistics for 103538 confinements (93892 Black and 9646 White confinements) were collected from 14 hospitals, clinics and nursing homes and for 56210 confinements (40612 Black and 15598 White confinements) birth statistics were collected from the Johannesburg City Health Department.

Annual TRs were calculated for each population group. The annual TRs showed considerable variation. This was particularly marked in the smaller Coloured and Indian population samples in which the sampling effect would have been greatest. Correlation coefficients were calculated to examine whether a true underlying relationship existed between the two variables (twinning rate and time) and a t-test was then used to examine whether the correlation coefficients were significantly different from zero. The equation describing the relationship between $x$ and $y$ (time and twinning rate) was obtained via regression analysis. ${ }^{15,16}$

\section{Results}

The number of twin confinements per 1000 confinements for each year is shown for each population group in Figure 1. No increase or decrease in the TR was immediately apparent in the White population. Both the Coloured and Indian populations showed a 


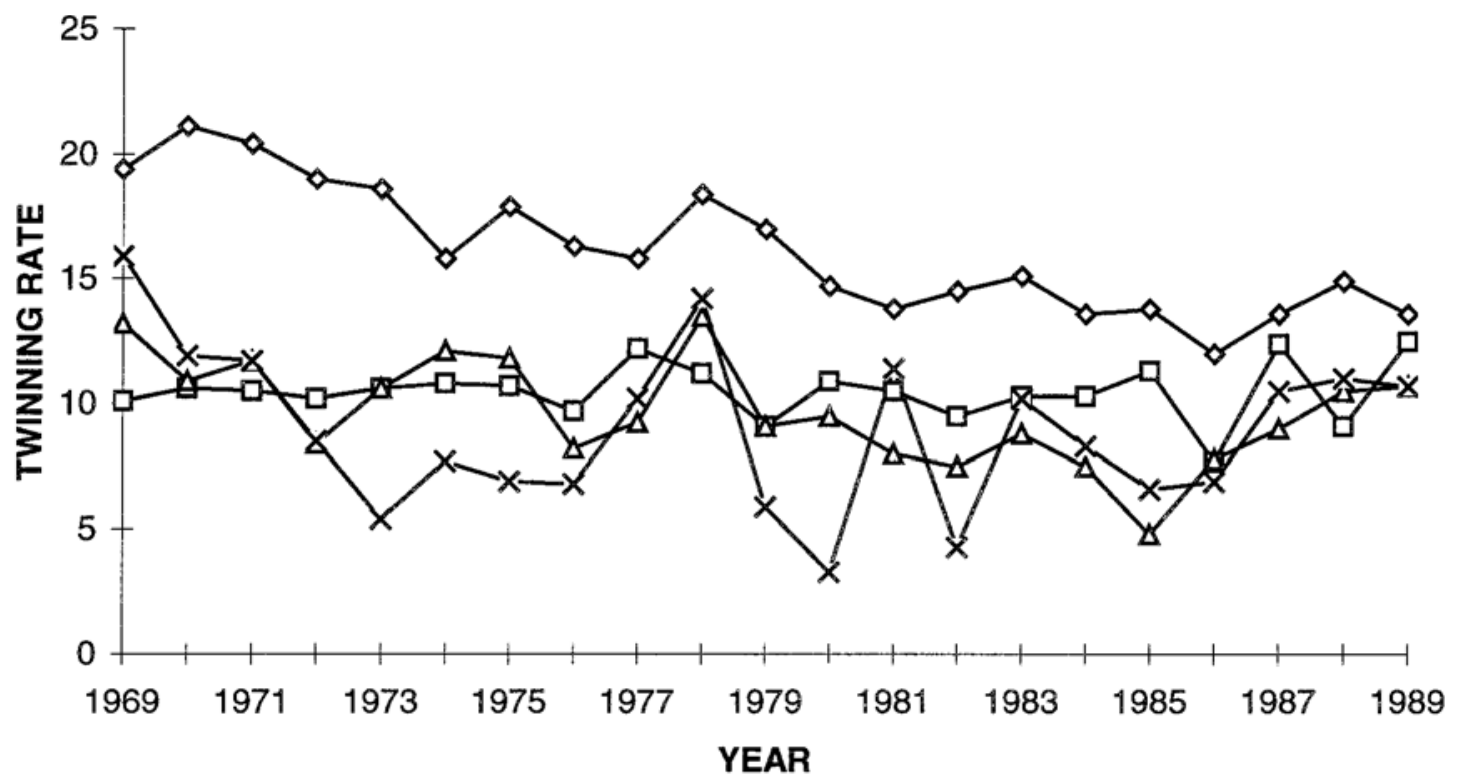

$\leadsto$ BLACK $\rightarrow-$ WHITE $\rightarrow-$ COLOURED $\quad-x-$ INDIAN

Figure1 Annual TRs of South African population groups in the Johannesburg Metropolitan Region 1969-1989

slight decrease in TR over the 21-year period and the Black population showed a marked decline in TR.

A summary of the results of correlation and regression analyses of TRs on year for each population group is shown in Table1. A t-test was carried out for each correlation coefficient $(r)$ to determine whether the relationships between changes in TR over time were significant.

There was no significant decline in either the White or Indian TR over the period from 1969 to 1989. Both the Black and the Coloured populations showed a significant decline in TR over this period, al though the slope of the regression line $(\beta)$ shows a much steeper decline in the Black than in the Coloured population (gradients $=-0.37$ and -0.17 respectively). Note should be taken, however, of the larger standard error of $\beta$ in the Coloured and Indian

Table 1 Results of correlation and regression analyses and significance tests examining the trends in twinning rates over time, 1969-1989

$$
r \quad(\beta)
$$

population (correlation (slope of the SE of Significance group coefficient) regression line) $(\beta)$ t level

\begin{tabular}{llrlll}
\hline Black & 0.78 & -0.37 & 0.04 & $8.18 \mathrm{P}<0.001$ \\
White & 0.00 & 0.00 & 0.04 & 0 & $\mathrm{NS}^{*}$ \\
Coloured & 0.25 & -0.17 & 0.07 & $2.52 \mathrm{P}<0.05$ \\
Indian & 0.03 & -0.10 & 0.12 & $0.75 \mathrm{NS}^{*}$ \\
\hline
\end{tabular}

*NS= Not significant, ie $P>0.05$. data compared with the other populations, reflecting their smaller population samples.

The trends in MZTR and DZTR over the 10-year period from 1969 to 1978 are presented in Figure2. This figure shows a large annual fluctuation in MZTR in both the Black and White populations but little difference between the MZTRs of these populations in any one year. The annual fluctuations in MZTR in the Black and White populations showed a close resemblance to one another. This suggests that some environmental factor, or factors, that affected both population groups may have had a significant effect on the MZTR. However, no overall increase or decrease was discernible. In contrast, the DZTRs in the Black and White populations showed marked differences. No definite increase or decrease was apparent in the White DZTR but the Black DZTR appeared to decline steadily over the 10-year period.

The relationships between MZTR, DZTR and year were examined quantitatively via correlation and regression analyses, the results of which are shown in Table2. No significant association between changes in MZTR and time was found in either of the population groups examined. The only significant association between DZTR and time was found in the Black population for which the correlation coefficient $(r)$ was 0.65 . The slope of the regression line $(\beta)$ for Black DZTR on year was $-0.49 \pm 0.13$ indicating a decline in DZTR over time. It is probable, therefore, that the decline in Black TR over 


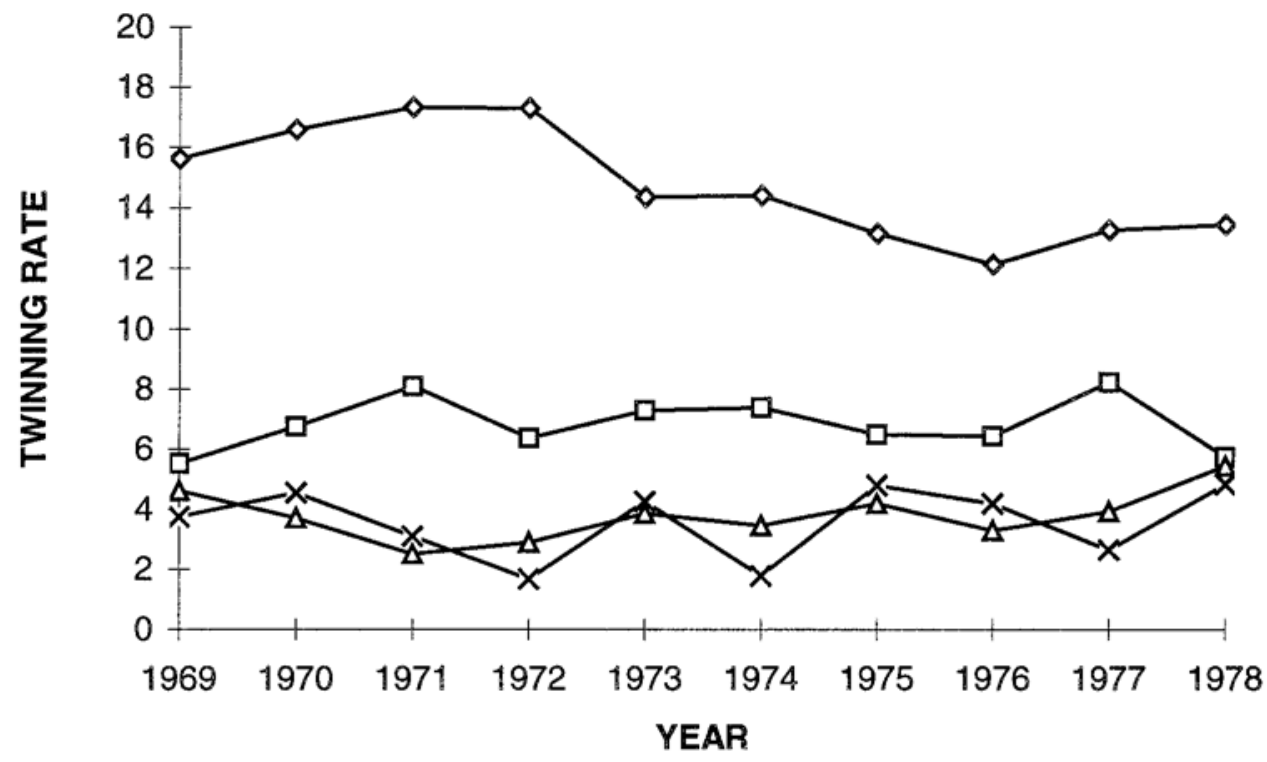

Figure2 Estimated annual DZTRs and MZTRs in the Johannesburg Metropolitan Region, 1969-1978

Table 2 Summary of correlation and regression analyses of (a) MZ TR and (b) DZ TR on year for the period 1969-1978

\begin{tabular}{llllll}
\hline & $r$ & $\beta$ & & \\
population & (correlation & (slope of the & SE of & & Significance \\
group & coefficient) & regression line) & $(\beta)$ & t & level \\
\hline
\end{tabular}

\begin{tabular}{llllll}
\hline $\begin{array}{l}\text { (a) MZ TR on } \\
\text { year: }\end{array}$ & & & & & \\
Black 0.02 & 0.05 & 0.14 & 0.4 & $\mathrm{NS}^{*}$ \\
White 0.13 & 0.1 & 0.09 & 1.09 & $\mathrm{NS}^{*}$ \\
(b) DZ TR on & & & & & \\
year: & & & & & \\
Black & 0.65 & -0.49 & 0.13 & 3.87 & $\mathrm{P}<0.02$ \\
White & 0.01 & 0.03 & 0.11 & $0.28 \mathrm{NS}^{*}$ \\
\hline
\end{tabular}

*NS= Not significant, ie $\mathrm{P}>0.05$. the past two decades may be explained by a decline in Black DZ twinning.

The estimated annual TRs for the Black and White populations of the Johannesburg Metropolitan Region for the period from January 1988 to December 1990 calculated from City Health Department birth statistics and from hospital, nursing home and maternity clinic birth statistics are shown in Table 3 . As these data were collected from different sources no direct comparison is possible. However, the estimated annual TRs appear to follow the same trends in both sets of data. It is difficult to establish definite trends over such a short period but the Black TR appears to have continued to decline until the end of 1990. Correlation and regression analyses of

Table 3 Annual TRs calculated from two data sources and results of correlation and regression analyses and significance tests examining the trend in TR over time, 1988-1990

\begin{tabular}{|c|c|c|c|c|c|c|c|c|}
\hline $\begin{array}{l}\text { population } \\
\text { group }\end{array}$ & year & $\begin{array}{l}\text { TR calc. from } \\
\text { City Health } \\
\text { Department } \\
\text { birth statistics }\end{array}$ & $\begin{array}{l}\text { TR calc. from } \\
\text { Hosp. Maternity } \\
\text { Clinic and } \\
\text { Nursing Home } \\
\text { birth statistics }\end{array}$ & $r$ & $\begin{array}{l}\beta \\
\text { (slope of the } \\
\text { regression line) }\end{array}$ & SE of $\beta$ & $t$ & $\begin{array}{l}\text { significance } \\
\text { level }\end{array}$ \\
\hline Black & $\begin{array}{l}1988 \\
1989 \\
1990 \\
{ }^{*} n\end{array}$ & $\begin{array}{l}14.9 \\
13.6 \\
13.6 \\
40612\end{array}$ & $\begin{array}{l}12.8 \\
12.2 \\
12.0 \\
93892\end{array}$ & 0.96 & -0.43 & 0.09 & 4.9 & $P<0.05$ \\
\hline White & $\begin{array}{l}1988 \\
1989 \\
1990 \\
{ }^{*} n\end{array}$ & $\begin{array}{l}9.1 \\
12.5 \\
10.9 \\
15598\end{array}$ & $\begin{array}{r}8.9 \\
13.5 \\
10.2 \\
9646\end{array}$ & 0.11 & 0.44 & 1.24 & 0.35 & $\mathrm{NS}^{* *}$ \\
\hline
\end{tabular}

${ }^{*} \mathrm{n}=$ Total number of birth statistics for the three year period.

${ }^{*} \mathrm{NS}=$ Not significant, ie $\mathrm{P}>0.05$. 
the hospital and clinic data, summarised in Table 3 , indicates that the decrease in TR in the Black population was significant up until the end of 1990.

\section{Discussion}

The trends in TRs in four different population groups in South Africa were examined over the 21-year period from 1969 to 1989. There was a significant decline in the Black TR over this period, and a smaller but still significant decline in the Coloured TR. Neither the White nor the Indian populations showed a significant change in TR over the period studied. Several studies of populations el sewhere in the world have shown a decline in TR during the twentieth century. In most of the studies reviewed the TR either stabilised or began to increase again around the mid to late 1970 s. $^{4-10}$ If the White population of South Africa, which is mainly Western European in origin, has followed the trends of other European populations, no significant decline in TR would be expected over the period 1969 to 1989. What could be the cause of the decline in Black TR over this period? Of the many theories that have been proposed to explain the decline in TR observed in other countries, four may be relevant to the Black population of South Africa, viz:

- a declining mean maternal age and parity;

- an increase in the use of contraceptives;

- psychosocial factors; and

- an increase in the spontaneous abortion rate.

Each of these theories is briefly examined below.

The term parity, as it is used in this study, is defined as the number of previous confirmed pregnancies a woman has had, irrespective of whether these resulted in a live or stillbirth, or a confirmed abortion, and discounting the current pregnancy. ${ }^{14}$ No records of maternal age and parity were available from the City Heal th Department birth statistics used for this study. However, information collected for a prospective case-control study of twins and single children, and their mothers, from 14 hospitals, nursing homes and maternity clinics in the Johannesburg Metropolitan Region provided data on the maternal age and parity of 3869 mothers who had given birth between January 1988 and December $1990 .{ }^{14} \mathrm{~A}$ comparison of the maternal age and parity distributions of the Black population, which had shown a decline in TR, with the White population which had not, indicated that Black mothers showed a broader distribution of both maternal age and parity than White mothers. The White population had a higher percentage of mothers with a maternal age of 26 or above $(73 \%$ of White mothers compared to $65 \%$ of Black mothers). However, there was no significant difference in the percentage of mothers giving birth after the age of $30(30 \%$ of White mothers compared with $34 \%$ of Black mothers). Among the mothers giving birth after the age of 26 a significantly greater percentage of Black mothers were of parity 3 or more compared with White mothers $(37 \%$ of Black mothers compared with $13 \%$ of White mothers). ${ }^{14}$ These figures give no indication of the trends in mean maternal age and parity over time of mothers in these population groups. However, they indicate that for declining maternal age and parity to have been the cause of the observed decline in Black TR over the past two decades, the percentage of mothers giving birth at a later age (30 years and above) and higher parity (parity 3 or above) in this population group must have been much higher in 1969 than in 1990. In addition, the differences between these percentages in the Black population and the White population would al so be expected to have been significantly greater in 1969 than the differences observed in 1990. Unfortunately, the researchers know of no analysis of maternal age and parity distribution among childbearing women in South Africa either before or during the two decades covered in this retrospective study.

A further analysis of South African population statistics for this period is needed to examine these factors in more detail. However, before such a study is proposed, it is interesting to note that several studies of Western European populations which reveal a marked decline in both family size and the greatest age at which women have continued childbearing, over the past century, have shown that these factors were not sufficient to explain the full extent of the observed decline in TR in these populations. ${ }^{9,17-19}$.

In some countries the decline in TR has been attributed to the increased use of oral contraception $^{9,18,20}$ and some studies report a lower DZTR among former contraceptive users. ${ }^{21-24}$ In a casecontrol study, in another section of the present study reported elsewhere, ${ }^{14} 21 \%$ of Black mothers had used oral contraception prior to conception of either twins or a single infant, compared with $56 \%$ of White mothers. Another $21 \%$ of Black mothers did, however, use an injected contraceptive, making a total of $42 \%$ of all Black mothers in the study who had used some form of hormonal contraception prior to conception of either twins or a single child. This was still significantly less $(P<0.001)$ than the percentage of White mothers who had used the same types of contraception. In addition, $44 \%$ of all Black mothers had used no form of contraception, either 
within a period of 6 months before conception, or between the birth of the previous child and the conception of the twins or single infant included in the study. ${ }^{14}$ Therefore, although it is probable that the use of hormonal contraception in both the Black and Coloured populations has increased over the past two decades, still a significantly smaller proportion of Black compared with White women used any form of hormonal contraception. A study of the characteristics of twin mothers has indicated that the use of oral or injected contraception appears to increase the chances of twinning, ${ }^{14}$ in agreement with other studies. ${ }^{21,25-28}$. These facts suggest that the recent decline in the Black TR was probably not the result of an increase in the use of oral contraception among Black women.

In some studies in other countries the decline in TR has been related to an increase in industrialisation and urbanisation ${ }^{1}$ and population density, ${ }^{2,29}$ resulting in 'psycho-social stress' ${ }^{3}$. The South African population studied here resided in the Inner Zone of the Johannesburg Metropolitan Region, ie in an urban area of South Africa. However, the high population growth rate, immigration of Black people from the rural areas into the region, the breakdown of family structure and the continuing urbanisation of a society that was traditionally agricultural ${ }^{30}$ may have all produced an environment in which psychosocial stress was a significant factor at the time of this study. It seems possible, therefore, that psychosocial stress factors may be responsible, at least in part, for the decline in TR in the Black population over the past two decades. It is not possible to substantiate this theory with the data available from the present study. However, the fact that a prospective study of TRs from 1988 to 1990 showed a possible continuing decline in Black TR, coupled with the knowledge that psychosocial stress factors in the area increased over this period in terms of a continuing increase in population density and political strife, does not contradict the theory.

Finally, it has been observed but, so far, not documented that the incidence of sexually transmitted disease increased sharply in the Black population over the past decade (Hitzeroth H, 1990 Africa Institute of South Africa, Pretoria, personal communication). It has been suggested that this may have caused an increase in spontaneous abortions and thus may have been a contributing factor in the decline in TR observed in the Black population in this study (England M and Maclntyre J, 1990, Baragwanath Hospital, Soweto, personal communication). However, Benson Keith and Keith in 1983, in their examination of the world-wide decline in twinning rates, observed that an increase in spontaneous abortions should have a similar effect upon both $M Z$ and DZTRs. ${ }^{17}$ Reports of both the world- wide decline in $\mathrm{TR}^{1,7,10,11,17}$ and the present data show the decline to be explained mainly by a decline in DZTR. The possible increase in spontaneous abortions cannot, therefore, adequately explain the decline in Black TR observed in this study, but it does warrant further investigation. James (1978) suggested that a decline in TR and particularly DZTR may be associated with a decrease in 'fecundability' or the probability of conception. ${ }^{31}$ There is some evidence of a downward trend in national fertility in South Africa over the past four decades, particularly in the Coloured population. White fertility declined to a replacement level (2.1) by the beginning of the 1980 s, and the Indian population was not far off this level. A substantial decline in fertility occurred in the Coloured population from 5.4 in 1950 to 2.3 by the 1990s. Estimates for the Black population also indicate a steady decline in fertility since the 1950s but no actual figures are available. ${ }^{32}$ Here again a further analysis of South African birth statistics is required to provide more information.

The TRs in the Johannesburg Metropolitan Region calculated from City Health Department birth statistics collected from 1988 to 1990 were: 13.8 and 10.77 for the Black and White populations respectively. TRs for this period calculated from the combined birth statistics of 14 hospitals, nursing homes and maternity clinics across the region were: 12.4 and 10.88 for the Black and White populations, respectively. A comparison with other studies shows that the TR among the Black population of the Johannesburg Metropolitan Region was lower than that found in other African countries (eg 23.8 twins/ 1000 births in Nigeria), ${ }^{19}$ whilst the TR of the White population in the present study was similar to TRs reported for other Caucasoid populations (10 twins/1000 births in the UK and USA, ${ }^{33} 10-12$ twins/ 1000 births in the USA). ${ }^{34}$ The lower TR in the Black population studied here compared to TRs calculated for other African countries may reflect the difference between the TRs found in urban and rural communities. The declines in DZ twinning in other countries are reported to have been steeper in urban than in rural areas. ${ }^{35}$ An examination of TRs among rural communities in South Africa would provide valuable information on the comparative TRs of people within this country of the same population group living under different sociological conditions. The decline in Black twinning, which appears to have continued at least until the end of 1990, is in contrast to trends observed both in the White population of South Africa and in several other populations worldwide. $^{4-9,12}$ The factors that contributed to the decline in Black DZTR in South Africa may be the same factors that contributed to the decline in DZTR earlier this century elsewhere in the world. Alternatively they may be unique to the Black population 
of South Africa. In either case a continued investigation of TR trends in South Africa may provide information not only on factors affecting TR in this country but also on the reason for the earlier decline in TR seen in other countries.

\section{Conclusion}

A significant decline in TR was observed in the Black and Coloured population groups of the Johannesburg Metropolitan Region of South Africa during the period from 1969 to 1989. This trend appears to have continued in the Black population at least until the end of 1990. During the first 10 years of the period from 1969 to 1989 it was established that the decline in Black TR could be accounted for by a decline in DZTR. The number of Coloured twin births during this 10-year period was not sufficient to establish TR trends within zygosity for this population group. Four factors may feasibly have affected the Black population in such a way as to produce a decline in TR, viz.:

- decreasing mean maternal age and parity;

- an increased use of hormonal contraceptives;

- an increase in the spontaneous abortion rate; and

- an increase in psychosocial stress factors.

Further study is necessary, however, to examine how these factors may specifically affect dizygotic twinning.

Despite the decline in the Black TR observed over the past two decades, the TR of this population group remains higher than that of the White population of South Africa. The TR of the Black population of South Africa is, however, lower than that recorded for Black populations in other parts of Africa.

\section{Acknowledgements}

The authors would like to express their sincere thanks to Dr GN Padayachee, $\mathrm{MOH}$ Johannesburg, for allowing access to the birth statistics of the Johannesburg City Health Department and to Mrs C du Toit for all her assistance in the Birth Records Office of that Department. They would also like to thank all the Matrons in charge of Maternity and the Ward Sisters in the Labour Wards of the participating hospitals and nursing homes for their kind cooperation. In particular the authors would like to thank
Drs Keith Bolton, Mike England and James Maclntyre, of Baragwanath Hospital and Dr Simon Levine of Coronation Hospital for all their assistance. Finally, they would like to thank the South African Institute for Medical Research for supporting the project.

\section{References}

1 Doherty $\mathrm{DH}$, Lancaster PAL. The secular trend of twinning in Australia 1853-1982. Acta Genet Med Gemellol 1986; 35: 61-76.

2 Eriksson AW, Eskola MR, Fellman JO. Retrospective studies on the twinning rate in Scandinavia. Acta Genet Med Gemellol 1976; 25: 29-35.

3 Parisi P, Caperna G. Twinning rates, fertility and industrialization: A secular study. In: Human Genetics Part A: The Unfolding Genome. New York: Allen R Liss, 1982, 375-394.

4 Allen G. The non-decline in US twin birth rates 1964-1983. Acta Genet Med Gemellol 1987; 36: 313-323.

5 Allen G, Parisi P. Trends in monozygotic and dizygotic twinning rates by maternal age and parity. Further analysis of Italian data 1949-1985, and rediscussion of US data 1964-1985. Acta Genet Med Gemellol 1990; 39: 317-328.

6 Bønnelykke B, Søgaard J, Niel sen J. Seasonality in twin birth rates, Denmark 1963-84, JEpidemiol Community Health 1987; 41: 338-343

7 Bressers WMA, Eriksson AW, Kostense PJ, Parisi P. Increasing trends in the monozygotic twinning rate. Acta Genet Med Gemellol 1987; 36: 397-407.

8 Imaizumi Y. The recent trends in multiple births and stillbirth rates in Japan. Acta Genet Med Gemellol 1987; 36: 325-334.

9 Parazzini F, Tozzi L, Mezzanotte G, Bocciolone L, LaVecchia C, Fedele L, Benzi G. Trends in multiple births in Italy: 1955-1983. Br J Obstet Gynaecol 1991; 98: 535-539.

10 Chen C-J, Lin T-M, Chang C, Cheng Y-J. Epidemiological characteristics of twinning rates in Taiwan. Acta Genet Med Gemellol 1987; 36: 335-342.

11 Imaizumi Y, Inouye E. Multiple birth rates in Japan: Further analysis. Acta Genet Med Gemellol 1984; 33: 107-114.

12 Schmidt HD, Rösing FW, Schmidt DE. Causes of an extremely high local twinning rate. Obstet Gynecol Survey 1983; 39: 266-268

13 Nurse GT, Weiner JS, Jenkins T. The Peoples of Southern Africa and their Affinities. Oxford: Oxford University Press, 1985.

14 Hain FM. Aspects of twinning in selected South African population groups. MSc Dissertation, Johannesburg, South Africa. 1994.

15 Bailey NTJ. Statistical Methods in Biology. English University Press (Unibooks): London, 1972.

16 Kirkwood BR. Essentials of Medical Statistics Oxford: Blackwell Scientific Publications, 1989.

17 Benson MD, Keith LG, Keith M. The Etiology of Twins. In: JM Leventhal (ed). Current problems in obstetrics and gynecology. Chicago: YearBook Medical Publishers, 1983VI, 8: 4-46.

18 Doherty $\mathrm{DH}$. Fertility, fecundity and twinning: A comparison of the trends in birth and twinning in Australia from 1854-1982. Acta Genet Med Gemellol 1988; 37: 119-125.

19 Marinho AO, Ilesanmi AO, Ladele OA, Asuni OH, Omigbodun A, Oyejide CO. A fall in the rate of multiple births in Ibadan and Igbo Ora, Nigeria. Acta Genet Med Gemellol 1986; 35: 201-204. 
20 Baena de Moraes MH, Beiguel man B, Krieger H. Decline of the twinning rate in Brazil. Acta Genet Med Gemellol 1989; 38: 57-63.

21 Harlap S. Multiple births in former oral contraceptive users. $\mathrm{Br}$ J Obstet Gynaecol 1979; 86: 557-562.

22 Hémon D, Berger C, Lazar P. Twinning following oral contraceptive discontinuation. Int J Epidemiol 1981; 10: 319-320.

23 Royal College of General Practitioners. Oral contraception study: The outcome of pregnancy in former oral contraceptive users. Br J Obstet Gynaecol 1976; 83: 608-616.

24 Vessey M, Meisler L, Flaver R, Yeates D. Outcome of pregnancy in women using different methods of contraception. Br J Obstet Gynaecol 1979; 86: 548-556.

25 Benirschke K, Kim CK. Multiple pregnancies. N Engl J Med 1973; 288: 1276-1284.

26 Bracken MB. Oral contraception and twinning: An epidemiologic study. Am J Obstet Gynecol 1979; 133: 432-434.

27 Harlap S, Eldor J. Births following oral contraceptive failures. Obstet Gynecol 1980; 55: 447-452.

28 Rothman KJ. Fetal loss, twinning and birth weight after oral contraception use. N Eng J Med 1977; 297: 486-471.
29 Allen G, Schachter J. Ease of conception in mothers of twins. Soc Biol 1971; 18: 18-27.

30 Morris P. Soweto: A Review of Existing Conditions and Some Guidelines for Change. Johannesburg: Transvaal Region of the Urban Foundation, 1980.

31 James WH. A hypothesis on the declining dizygotic twinning rates in developed countries. In: Nance WE, Allen G, Parisi P (eds). Twin Research 24 Part B, New York: Allen R. Liss 1978, 81-88.

32 Chimere-Dan O. Demographic Patterns. In: Harrison D, Nielson M (eds). South African Health Review 1995 Health Systems Trust and Henry J. Kaiser Family Foundation: Durban, 1995.

33 Bryan E. The Nature and Nurture of Twins. Philadelphia: Baillière Tindall, 1983.

34 Hollenbach KA, Hickok DE. Epidemiology and diagnosis of twin gestation. Clin Obstet Gynecol 1990; 33(i): 3-9.

35 Katsouyiannopoulos V. The falling twin rate in Greece. J Epidemiol Community Health 1981; 35: 218-219. 